\title{
Com o que, de fato, a terapia comportamental trabalha?

\author{
Um depoimento pessoal de um \\ terapeuta comportamental.
}

Harald W. Lettner, Ph.D.**

A

terapia comportamental (T.C.) tem como objetivo bem claramente definido o de resolver (ou pelo menos tentar resolver) qualquer problemática psicológica que um indivíduo possa estar experimentando e de (re)instituir um funcionamento psicologicamente adequado e, portanto, satisfatório para este indivíduo. Como veremos mais adiante, isso $\mathrm{NA} O$ significa um tratamento "sintomatológico" ou "mecanicista" - uma vez que esta abordagem é baseada no modelo sócio-psicológico que elimina o conceito de "doença subjacente" e, portanto, também de sintomas, através dos quais esta doença se manifestariamas SIM um tratamento das queixas apresentadas além dos macanismos psicológicos funcionalmente envolvidos no desenvolvimento e na manutençào desta problemática. Isto, obviamente, necessita de um entendimento geral e específico do cliente $\mathrm{cm}$ termos de seu funcionamento atual (principalmente os fatores de manutenção da problemática) e da história de vida que resultou no quadro atual.

** Protessor da Pós-Graduação em Psicologia Clínica da PUC/RJ e Diretor do Instituto de Psicorerapia Comportamental - Clínica Médica e Psicológica Ltda.
O $1^{\circ}$ passo, então, na T.C. é de se alcançar um entendimento (o que é o contrário de uma posição mecanicis. ta), através de uma análise funcional dos fatores:

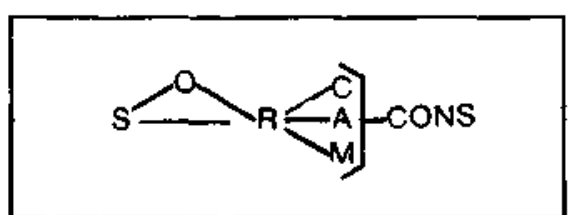

Aqui, $S$ significa estímulo, o que é qualquer evento ou acontecimento externo ou interno capaz de desencadear determinada resposta (R). Raramente esta ligação (S-R) é direta - na realidade isto só acontece nos reflexos. O resto do comportamento tem u m fator intermédiário $\mathrm{O}=$ organismo; aqui entram fatores como predisposiçào neuro-fisiológicas (por exemplo, hiper-reatividade do sistema nervoso, etc.), predisposiçōes pessoais (por exemplo, neuroticismo, introversão - extroversão, etc.), experiências passadas, educação, moral, religião, etc., que funcionam como um "filtro" influenciando a percepção do estímulo e a scleção da respos-

- Este artigo é um resumo de uma palestra apresentada no Congresso da SBPC, em São Paulo, em julho de 1988. ta específica a ser emitida. A resposta R sempre consiste de três níveis diferentes: $C=o$ nivel cognitivo que compreende todos os eventos mentais como, por exemplo, pensamentos. idéias, impulsos, desejos, etc:; $\mathrm{A}=$ " nível das respostas do sistema nervoso autònomo como, por exemplo, taquicardia, tensão muscular, tremor, sudorese, etc.; e $\mathrm{M}=$ o nivel das respostas motoras, tudo que a pessoa realmente faz.E, finalmente, cons = as conseqüências de determinada reação ( $C, A$ e $M$ ) que podem ser externas e/ou internas como, por exemplo, alívio, crítica ou aprovação por outros, culpa, etc.

Nesta análise funcional o terapeuta se comporta como un 'detetive' formulando hipoteses a respeito da problemática, submetendo-as a verificaçōes, inicialmente através da lógica de entrevista, com o objetivo de gradualmente aumentar a confiabilidade de suas suposiçōes a respeito do funcionamento do cliente (ao contrário do psić́logo tradicional que tira as suas conclusőes de entrevistas e testes questionáveis sem expor essas suposiçōes à qualquer verificaçăo). Em outras palavras, trata-se de uma tentativa de aplicar o modelo experimental ao processo de obtenção de entendi- 
mento da problemática do cliente com a finalidade de fornecer: 1) insight para o cliente (que não é suficiente para resolver os problemas mas, sim, motiva-o para se desempenhar no tratamento em si) e 2) conhecimento dos fatores envolvidos principalmente na manutenção da problemática, para servir como base para o planejamento da intervenção terapêutica, que é, portanto, desenvolvida individualmente "à medida" para cada cliente e sua problemática. Esta avaliação (que demora normalmente em torno de quatro consultas) tem, então, como objetivo desenvolver uma formulação dos problemas, ou seja: a) uma definição operacional da problemática, b) identificação objetiva dos fatores do desenvolvimento e principalmente da manutenção da problemática, c) indicaçōes terapêuticas diretas e d) o seu prognóstico.

O terapeuta, nesse contato inicial com o cliente, já tenta desenvolver um relacionamento com ele, mas o relacionamento terapêtutico em si, como $2^{\circ}$ passo, (no sentido de ser uma interação entre duas pessoas mais favorável à produção dos objetivos terapêuticos) se desenvolve baseado na formulação que indica diretamente o tipo de interação mais apropriada. Embora a T.C. sempre exija verificação empírica ou experimental (que quase não existe nestá área), a maioria dos terapeutas comportamentais usa procedimentos de desenvolvimento de relacionamentos interpessoais (sejam eles Rogerianos ou de qualquer outro tipo). Estamos atualmente, na PUC/RJ, executando a primeira tentativa de operacionalização dos fatores favoráveis a um relacionamento terapêutico e sua verificação, com o objetivo de criar uma base mais objetiva para esta área. Os primeiros resultados estão sendo publicados na revista "Estudos em Psicologia", da PUCCAMP. Basicamente o terapeuta desenvolve um relacionamento único com cada cliente; formas padronizadas de interação, como por exemplo, ser empático e caloroso com cada indivíduo, significam ignorar diferenças individuais, certamente inapropriado e podem, sob certas condiçōes, até prejudicar o cliente.

Somente depois de ter desenvoldido a formulação (como definida acima) da problemática, o terapeuta parte, como 3 passo, para o planejamento das intervençōes terapêuticas necessárias para resolver o problema. Este "programa" terapéutico é individualmente desenvolvido "sob medida" para cada indivíduo e sua problemática (o que é o contrário de uma postura mecanicista). Dependendo dos fatores do desenvolvimento e da manutenção identificados na avaliação, junto com os seus mecanismos de interligação funcional, o terapeuta comportamental pode atuar numa série de áreas (atravếs de uma metodologia vasta e a cada ano maior), das quais apresentarei as mais importantes. A seqüência da apresentação é muito mais de ordem didática do que terapêutica e segue o esquema da análise funcional apresentada:

\section{Áreas de atuação}

1) O: predisposiçōes neurofisiológicas (por exemplo, hipótese de Lader e Wing), neuroticismo, introversão - extroversão, efeitos do passado (não o passado em si), da educação e de experiências anteriores, regras e crenças errôneas moralistas e religiosas, etc.

2) ligaçōes S-R: condicionamento clássico, discriminação, abstração, generalização, etc.

3) $R$ :

a) C-respostas cognitivas; pensamentos, idéias, impulsos, desejos, etc.

b) A-respostas autonômicas: taquicardia, palpitaçōes, produção de suco gástrico, alteraçōes de pressão sangüínea, tremor, sudorese, tensão muscular, etc.

c) C-A: as respostas cognitivas e autonômicas juntas compreendem as emoçōes, sentimentos e afetos.

d) M-respostas motoras: os comportamentos específicos que o indivíduo emite.

4) ligações R-cons.: contingências de reforço e punição, extinção, ganho secundário, eficácia relativa do comportamento na sua atuação sobre o ambiente, valor relativo do reforço e do reforçador, etc.

5) resistências: nem todas as dificuldades no processo terapêutico devem ser atribuídas a uma resistência do -cliente, muito pelo contrário, na realidade a maior parte tern que ser atribuída a erros no entendimento (e portanto no tratamento) do terapeuta. Ainda assim podem ocorrer resistências verdeiras que são analisadas $e$ trabalhadas dentro dos princípios dos ganhos secundários.
6) modelação-imitação: aprendizagem vicária aonde o terapeuta(e/ou seus ajudantes) funciona como modelo de forma apropriada para cada individuo.

7) fatores ambientais no nível de S e/ou cons.: por exemplo, situação familiar, trabalho, atitude ou atuação erradas de pessoas próximas.

8jregistros: durante a avaliação e a terapia são mantidos registros quantitativos e qualitativos para obter novas informações, verificar as suposições do terapeuta e para controlar eficácia da intervenção.

Durante esse processo terapêutico, o cliente aprende gradualmente a dominar e modificar o seu funcionamento, se tornando cada vez mais independente do terapeuta e das suas orientaçōes. Com esta forma de atuação, alcançam as porcentagens de sucesso terapêutico mais altas (em torno de $85-95 \%$ ), em relativamente pouco tempo (entre poucas semanas e mais ou menos um ano e meio), sem "substituição de sintomas" e com uma duração dos efeitos terapêuticos a longo prazo(já existem trabalhos de acompanhamento durante quase $\mathbf{2 0}$ anos).

Afinal, trata-se de uma abordagem terapêutica mundialmente reconhecida como uma das mais importantes na psicologia atual, que merece, aqui no Brasil, sem dúvida pelo menos melhor ensino de seus princípos e métodos, com o objetivo de eliminar esses preconceitos que existem por causa de tanta falta de conhecimentos corretos a seu respeito.

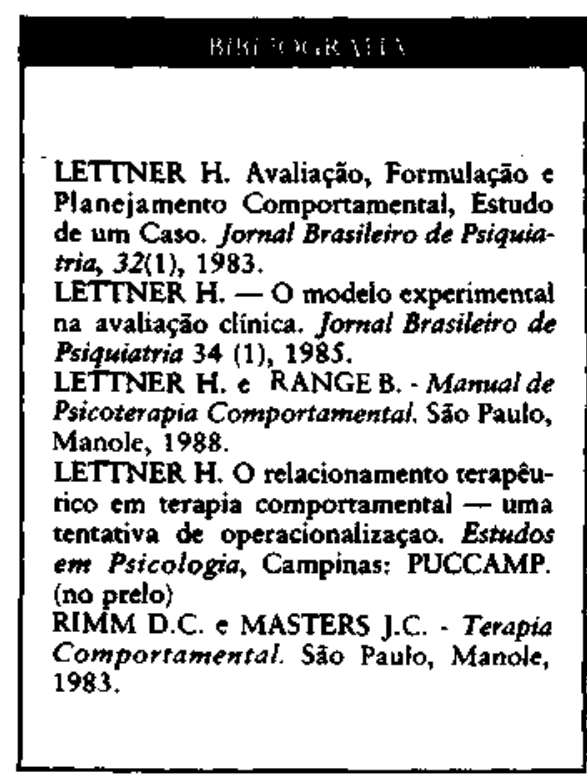

